Gary Poole, UNIVERSITY OF BRITISH COLUMBIA, gary.poole@ubc.ca

\title{
INTRODUCTION
}

\section{Weaving SoTL into Our Everyday Lives}

The third year of Teaching \& Learning Inquiry begins with articles that demonstrate a maturing view of the field. They explore the potential of the Scholarship of Teaching and Learning (SoTL) as a framework for doing more informed, higher quality work in course (re)design, national accreditation processes, and the analysis of problem-solving processes of teachers and learners. They illustrate one of the ways SoTL practitioners serve as what Bernstein calls "Cosmopolitan Assets to an Institution”: specifically, these faculty members habitually "acknowledge a formal body of expertise in their work and ... make reference to an external community when evaluating quality and seeking innovation in ideas and practices" (2013, p. 37-38). The work in these articles also reflects the "vision of academia's future" in which "inquiry, evidence, and innovation in teaching and learning are part of the fabric of everyday life"-and not just teaching and learning (Williams, Verwood, Beery, Dalton, McKinnon, Strickland, Pace, \& Poole, 2013, p. 50). Williams and colleagues illustrate this future by describing a committee that -instead of relying on assumptions and anecdotes - consults relevant research to more precisely frame, understand, and respond to what is perceived as a local campus problem.

In this future, and in this issue of TLI, approaching problems through the lens of SoTL is a mark of rigour. Auten and Twigg describe how SoTL informed the design and content of a graduate student pedagogy course to more effectively equip future teachers. deBraga, Boyd, and Abdulnour similarly used Felten's "principles of good practice in SoTL" to guide a course redesign aimed at higher-level thinking skills. They note that this framework, which began with student learning, was tied to relevant contexts, partnered with students, and opened itself to peer review, challenged students more effectively while also improving their course evaluations. Maurer and Kropp also describe increasing rigour-in this case, through a specific testing strategy — without negatively affecting student evaluations.

Lee and Son demonstrate how conversations about teaching, which often feature a comparison of practices, can be taken to a new level of rigour when those comparisons are made more systematically. Wismath, Orr, and MacKay apply the notion of threshold concepts to help us better understand how students approach problem solving. When instructors must become problem solvers, necessity can become the mother of their invention. Such was the case when Day turned to a clever use of educational technology to keep his course moving smoothly during a time that could have been disruptive. In doing so, he realized he had the makings of a natural experiment to measure the educational impact of his idea. His paper invites us all to find such SoTL opportunities. 
Indeed, all the articles in this issue of TLI present the same invitation-to consider SOTL as part of the "fabric of everyday life." As SoTL becomes more thoroughly woven into this fabric, fascinating questions get asked, research opportunities get pursued, and teaching and learning keep getting better.

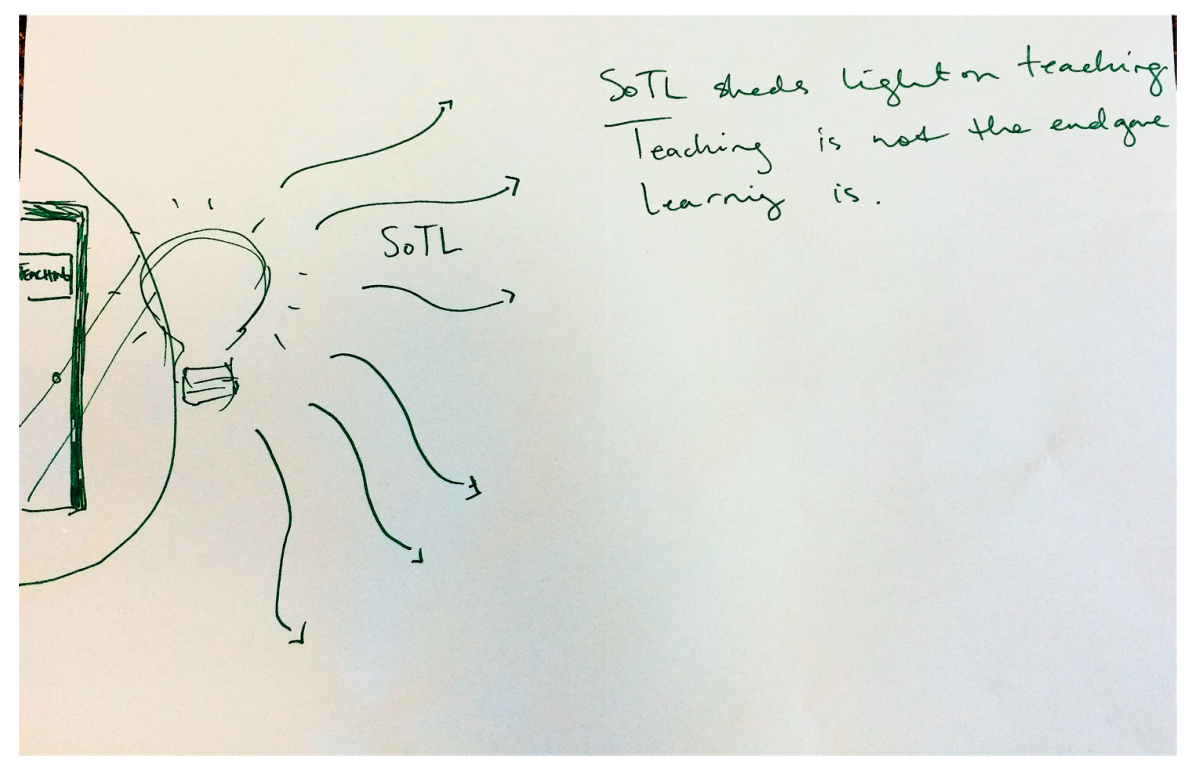

Figure 1. After a recent SoTL workshop, a participant submitted Figure 1 as the definition of SoTL, hinting at this understanding of SoTL as significant and useful beyond the classroom.

Gary Poole is the Associate Director of the School of Population and Public Health and a Senior Scholar in the Centre for Health Education Scholarship at the University of British Columbia.

Nancy Chick was Assistant Director of the Center for Teaching and an affiliated faculty member in the English Department at Vanderbilt University. She is now University Chair in Teaching and Learning, Academic Director of the Taylor Institute for Teaching and Learning, and Professor of English at the University of Calgary.

\section{REFERENCES}

Bernstein, D. (2013). How SoTL-active faculty members can be cosmopolitan assets to an institution. Teaching \& Learning Inquiry, 1(1). 35-40.

Williams, A. L., Verwoord, R., Beery, T. A., Dalton, H., McKinnon, K., Strickland, K., Pace, J., and Poole, G. (2013). The Power of social networks: A model for weaving the Scholarship of Teaching and Learning into institutional culture. Teaching \& Learning Inquiry, 1(2). 49-62. 